\title{
Reflections on the ISPOR Special Task Force on U.S. Value Frameworks: Implications of a Health Economics Approach for Managed Care Pharmacy
}

\author{
Louis P. Garrison, Jr., PhD; Peter J. Neumann, ScD; and Richard J. Willke, PhD
}

\section{SUMMARY}

In 2016, The Professional Society for Health Economics and Outcomes Research (ISPOR) formed a special task force (STF) to review approaches and methods to support the definition and use of high-quality U.S. value frameworks. As the leadership group of that initiative, we present our perspective, focusing on implications for the managed care pharmacy community.

Our reflections are organized by 9 key observations and conclude with a summary recommendation. We begin by emphasizing the importance of distinguishing among "perspectives" and "decision contexts." Possible perspectives include patient, payer, provider, health care sector, and societal. Decision contexts range from formulary inclusion to guideline development to clinical shared decision making, and multiple perspectives can be taken on each of these decisions. The STF focused on value in the context of including a new medicine in a formulary and, thus, health plan, using a health economics approach that compares marginal benefit (gross value) and marginal (opportunity) cost, yielding the net value.

Health care is unique compared with other markets. While economists often use market purchases as indicators of value, they also recognize that this does not work well in health care, since most patent-protected drugs are covered by insurance. To assess the likely health and economic impact, health economists often employ cost-effectiveness analysis, using the quality-adjusted life-year (QALY), a metric that combines mortality and morbidity into a single preference-based index. We strongly endorse the STF's recommendation that payers should use the cost-per-QALY metric as a starting point. However, like the STF, and many of those stakeholders who provided input, we recognize that this metric has some limitations in theory and in practice.

Nonetheless, the cost-per-QALY metric is a pragmatic tool that can be augmented to address some of its limitations by integrating other elements of value, particularly those related to uncertainty, such as financial risk protection, health risk protection, the value of hope, real option value, and the value of knowing. The resulting adjusted ratio can be compared with a willingness-to-pay threshold or combined in a measure of net monetary benefit. Alternatively, the array of elements can be valued using multicriteria decision analysis. We end with the key recommendation that further development and testing of these promising approaches is needed to improve the deliberative process of health technology assessment.

J Manag Care Spec Pharm. 2019;25(11):1185-90

Copyright $\odot 2019$, Academy of Managed Care Pharmacy. All rights reserved.
B ecause new value frameworks have recently gained visibility and some traction in the United States, and because questions have emerged about their underlying assumptions, ISPOR-The Professional Society for Health Economics and Outcomes Research-formed a special task force (STF) that produced a report in 2018 in the form of a series of papers that reviewed the approaches and methods underlying these frameworks, with the purpose of explaining their similarities and differences and their relevance to different health care sector decisions ${ }^{1-7}$ As the leadership group of that initiative, we present 9 overarching, related observations on the STF effort, focusing on implications for the managed care pharmacy community. These observations are sequenced to provide a groundwork for understanding the recommendations from the STF report, which are summarized in Table 1; each observation is followed by a reference to the relevant recommendations.

Observation \#1: To understand differences among existing and emerging value assessment frameworks, it is important to distinguish among "perspectives" and "decision contexts" (Recommendation I).

The emergence of various value assessment frameworks in the United States-including, but not limited to, those by the American College of Cardiology/American Heart Association, the American Society of Clinical Oncology (ASCO), the Institute for Clinical and Economic Review (ICER), Memorial Sloan Kettering Cancer Center, and the National Comprehensive Cancer Network-represent important attempts to provide better information on the value of prescription drugs and other health care technologies to payers, providers, and patients. ${ }^{1}$

A key objective of the STF report was to clear up confusion surrounding the use or potential use of these value frameworks. Notably, the frameworks differ in their missions, scope of activities, and methodological approaches. We emphasized that the frameworks focus on different types of decisionssome, such as the ICER framework, are geared towards coverage and reimbursement decisions, while others, such as the ASCO framework, are intended to support shared clinical decision making. ${ }^{2}$ Typically, health sector stakeholders, including patients, plan members, payers, providers, manufacturers, and society as a whole, have a point of view or perspective in the context of each of these decisions. 
Reflections on the ISPOR Special Task Force on U.S. Value Frameworks:

Implications of a Health Economics Approach for Managed Care Pharmacy

\section{TABLE 1 ISPOR Special Task Force Recommendations}

\begin{tabular}{|c|c|}
\hline Primary Recommendations & Key Points \\
\hline $\begin{array}{l}\text { I. Be explicit about decision context } \\
\text { and perspective in value assessment } \\
\text { frameworks. }\end{array}$ & $\begin{array}{l}\text { - No single value assessment framework captures everything. } \\
\text { - For societal and health plan resource allocation decisions (coverage/reimbursement), the perspective should } \\
\text { reflect those who pay for care (e.g., enrollees, employees, taxpayers). } \\
\text { - Well-designed patient-level frameworks can help guide shared decision making for treatment choices. }\end{array}$ \\
\hline $\begin{array}{l}\text { II. Base health plan coverage and } \\
\text { reimbursement decisions on an } \\
\text { evaluation of the incremental } \\
\text { costs and benefits of health care } \\
\text { technologies as is provided by cost- } \\
\text { effectiveness analysis. }\end{array}$ & $\begin{array}{l}\text { - Cost-per-QALY analyses have strengths and limitations. } \\
\text { - Frameworks that focus on coverage/reimbursement should consider cost per QALY, as a starting point. } \\
\text { - Consider elements not normally included in CEAs (e.g., severity of illness, equity, risk protection) but more } \\
\text { research is needed. }\end{array}$ \\
\hline $\begin{array}{l}\text { III. Develop value thresholds to serve } \\
\text { as an important input to help } \\
\text { guide coverage and reimbursement } \\
\text { decisions. }\end{array}$ & $\begin{array}{l}\text { - Assess value for money and compare to value threshold, allowing for other factors. } \\
\text { - In the United States, different payers could use different thresholds. } \\
\text { - Equity and severity of illness considerations may alter thresholds. }\end{array}$ \\
\hline $\begin{array}{l}\text { IV. Manage budget constraints and } \\
\text { affordability based on cost- } \\
\text { effectiveness principles. }\end{array}$ & $\begin{array}{l}\text { - Budget impact analysis is not integral to value assessment. } \\
\text { - Budget constraints and affordability can be addressed using current tools, e.g., delay or cost-effectiveness ratios. } \\
\text { - Over time, availability of new cost-effective technologies may affect overall spending. }\end{array}$ \\
\hline $\begin{array}{l}\text { V. Test and consider using structured } \\
\text { deliberative processes for health } \\
\text { plan coverage and reimbursement } \\
\text { decisions. }\end{array}$ & $\begin{array}{l}\text { - No existing method of aggregation is perfect. Pragmatic approaches are needed. } \\
\text { - Deliberative process is useful and important. } \\
\text { - Deliberative processes should consider explicit ACEA and MCDA. } \\
\text { - MCDA-with appropriate weights-could be helpful for patients choosing treatments. }\end{array}$ \\
\hline $\begin{array}{l}\text { VI. Explore and test novel elements of } \\
\text { benefit to improve value measures } \\
\text { that reflect the perspectives of plan } \\
\text { members and patients. }\end{array}$ & $\begin{array}{l}\text { - Develop more comprehensive economic evaluation. } \\
\text { - More research needed on ACEA and MCDA. } \\
\text { - Payers are agents for patients. Patient experience is central. }\end{array}$ \\
\hline \multicolumn{2}{|c|}{$\begin{array}{l}\text { Adapted from the ISPOR STF Report in Garrison LP, Neumann PJ, Willke RJ, et al. A health economics approach to US value assessment frameworks-summar } \\
\text { recommendations of the ISPOR Special Task Force report [7].7 } \\
\text { aFor ACEA, see Appendix in online article; for MCDA, see Figure 1. } \\
\text { ACEA = augmented cost-effectiveness analysis; CEA=cost-effectiveness analysis; ISPOR= The Professional Society for Health Economics and Outcomes Research; } \\
\text { MCDA = multicriteria decision analysis; QALY=quality-adjusted life-year. }\end{array}$} \\
\hline
\end{tabular}

Observation \#2: For managed care pharmacy, the question of which drugs to include in pharmacy and medical benefits is the key issue-and was the focus of the task force (Recommendations I \& II).

Economists traditionally think of value as revealed in marketplace transactions - what someone is willing to pay or give up (opportunity cost) to obtain a good or service. But the necessity of financing high-cost treatments for illnesses through risk pooling via insurance makes it difficult to use markets to assess willingness to pay and, hence, value. Physicians and health care payers are "agents" of the patients and plan members and make decisions and payments on their behalf. Hence, it can be difficult to pinpoint the perception of value that drives health care decisions.

The STF took a health economics approach to the concept of value in health care systems. Our approach followed basic microeconomic principles, while recognizing (a) certain limitations of those principles, particularly in relation to health care markets, and (b) the need to consider important issues, such as equity, that are not traditionally the focus of economics. First, "value" was defined from an economic perspective: "gross value" can be thought of as what someone would be willing to pay for an economic good or intervention, while "net value" subtracts the opportunity cost incurred to obtain that gross value. Thus, net value is what a consumer would be willing to pay in order to avoid losing access to the good or service, given what else is available. Second, because individuals vary in their preferences for health (as an economic good) versus other economic goods, the value they place on different health care interventions also varies. Third, since most medical care is purchased indirectly via health insurance, individuals do not directly face prices, and their agents (insurers and providers) acting on their behalf must assess the clinical and economic value of the services they can receive.

\section{Observation \#3: The question of which health products or services are included in the health benefits package is inherently a question of comparing benefits and costs, considering the perspectives of patients and plan members (Recommendation II).}

Our STF considered the perspectives of patients and health plan members. The latter are both potential patients (if they 
become ill) and the ultimate payers through health insurance premiums and taxes (and other out-of-pocket costs). ${ }^{2}$ Despite being the agent for the plan member-and hence the patientthe insurer perspective is likely to differ from the perspective of a patient when ill. When ill, patients may desire all potentially beneficial health care regardless of cost because they face only a fraction of the cost and because their illness is now certain and not just a probability. Because patients reveal their preferences in part through their choice to enroll in health plans, payers will presumably want to understand how patients value health outcomes. Hence, an outcome metric, such as quality-adjusted life-years (QALYs), should reflect patient preferences for health states and treatments as accurately as possible.

Still, premium-paying plan members face the full cost for the entire health plan population and must consider the value for money from spending on medical care versus other goods and services.

Observation \#4: Measuring health benefits of new and existing medicines in terms of the effect on patient mortality and morbidity via the QALY metric has proven to be a useful input and tool for health plan decision makers in many health systems and countries (Recommendations II-IV).

The QALY metric is used to adjust expected life-years to account for the potentially undesirable effects of treatments, illnesses, or conditions. One QALY is equivalent to 1 year of "perfect health." For example, potential patients might feel that 1 year spent with total blindness is equal in value to 6 months of perfect health, or one half of a QALY. In principle, any health state can be equated to some fraction of a perfectly healthy life-year. This fractional value is called a health state "utility." The expected years of survival following treatment, adjusted by health state utilities, constitute the expected QALYs from treatment.

The net health benefit of a treatment is the difference between the QALYs expected following the treatment being evaluated and the QALYs expected from an alternative (or no) treatment. This "incremental" aspect of treatment benefit is critical. Often, those conditions that yield the worst mortality or quality-of-life outcomes without treatment have the most to gain from treatment. An incremental approach, for benefits and costs, captures the "bang for the buck" of the treatment and is consistent with the benefit-cost approach used in economic evaluations of many interventions outside health care.

When used consistently for health care decisions, QALYbased cost-effectiveness analysis maximizes the population health gain for a given health care budget. Several countries, including the United Kingdom and Canada, use it as their standard approach for drug coverage decisions; many other countries consider cost-per-QALY results in their decisionmaking processes.
Observation \#5: Importantly, utility measurement is only 1 component of the QALY; the major advantage of this tool is to integrate mortality and morbidity into a single, intuitive measure - that is, equivalent gains in healthy life-yearsthat supports economic comparisons across different diseases and interventions (Recommendation II).

The QALY should be a carefully constructed combination of the 2 elements of treatment benefit that matter most to patients: survival and quality of life. ${ }^{3}$ Some treatments have a relatively stronger survival benefit (e.g., by preventing heart attacks), while others have a stronger quality-of-life benefit (e.g., by relieving pain). In order to compare and prioritize treatments across disease areas covered under a limited health plan or formulary budget, such a standardized measure is essential.

Two aspects of QALYs are important but often not well understood. First, utility values are derived from patients, as well as the general public. Patients provide detailed descriptions of their health states. Based on these descriptions, most commonly, the general public is asked to provide ratings of the disease health state utility, which allows the preferences of the typical plan enrollee (a member of the general public) to shape the expected QALYs from treatment and, thus, influence how their premium dollars are managed for coverage of different treatments. Second, health state utilities are calibrated to represent how the general public will "trade off" years of survival for improved quality of life, for example, a health state utility is pegged at 0.7 when people are indifferent to 10 years of survival in that health state versus 7 years of survival in perfect health. These attributes are critical to making QALYs fit for formulary decisions that involve patient and plan member interests regarding a portfolio of treatments that may affect survival or quality of life or both.

Observation \#6: The cost-per-0ALY metric does, however, have limitations in theory and in application and should be seen as a pragmatic tool to support some types of health care resource allocation decision making (Recommendations II-IV). Health economists recognize that QALY measurements do not perfectly capture all aspects of how patients and society perceive value in the health care system. There are some technical assumptions needed to make this metric workable-such as constant proportional tradeoffs between utility and survival time over a lifetime-that may imperfectly reflect actual preferences in some situations. Also, there can be deficiencies in how QALYs are measured in practice for some subgroups (e.g., children), for complex services (e.g., physician care), or for end-of-life situations. Furthermore, actual patients can cope and adapt to disability and may experience health states more favorably than they would have expected. In some situations, there may also be other significant elements of value, described below, that are not typically captured by standard approaches to constructing QALYs. 
Reflections on the ISPOR Special Task Force on U.S. Value Frameworks:

Implications of a Health Economics Approach for Managed Care Pharmacy

FIGURE 1 Multicriteria Decision Analysis for Comparison with ACEA Approach

Estimate Value for Each Intervention:

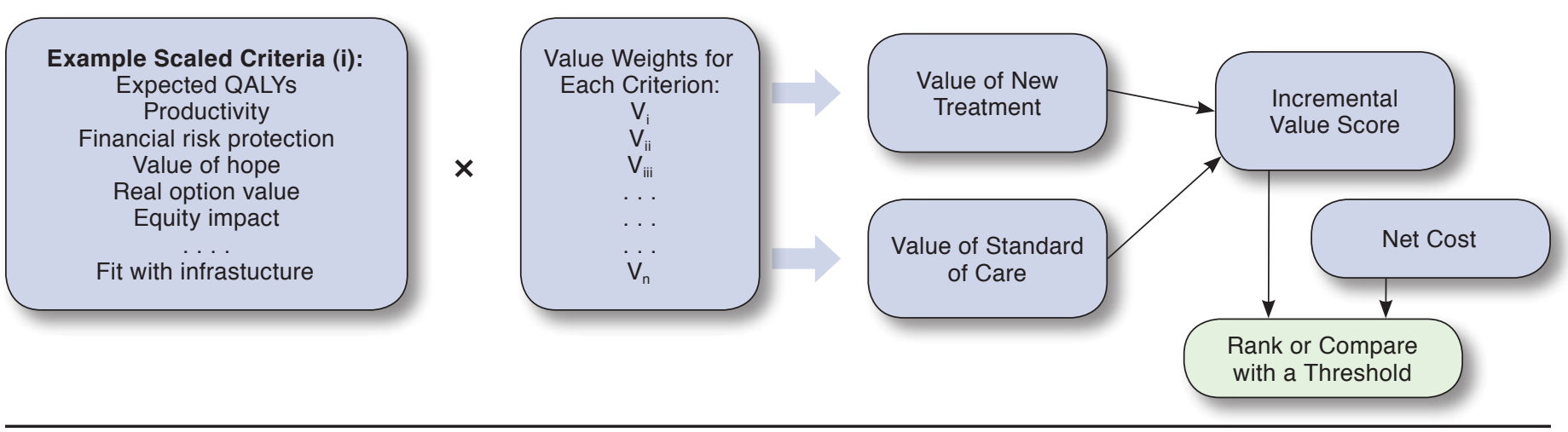

$A C E A=$ augmented cost-effectiveness analysis; $Q A L Y=$ quality-adjusted life-year

Despite these limitations, the QALY remains a useful core element of treatment benefit, and cost-per-QALY analysis is a useful starting point for measuring treatment value and use in health care resource allocation, such as drug coverage decisions. Sensitivity analysis can be used to measure the influence of key assumptions. Other factors-contextual, societal, and financial—can be measured and entered into the decision calculus as appropriate. Cost-per-QALY measures can anchor these decisions in the fundamental clinical benefits and health care costs to help guide the health care system to provide the greatest possible overall health benefit it can afford.

\section{Observation \#7: Although expected health gain-in terms of greater quantity or quality of life-is the major driver of most treatment decisions, other factors may also matter and should be considered. These other potential elements of value include financial risk protection, health risk protec- tion, the value of knowing, the value of hope, real option value, scientific spillovers, family spillovers, equity, and others (Recommendation II \& VI).}

Our STF suggested that a potential approach to incorporating other factors would be to perform "augmented" cost-effectiveness analysis (ACEA), which attempts to adjust the cost-perQALY metric for these other potential elements of value. ${ }^{3}$ The 2 basic ways to adjust the cost-per-QALY ratio are to adjust cost in the numerator or to adjust health state utilities in the denominator by adding attributes to health state descriptions. Like the recent U.S. Second Panel, ${ }^{8,9}$ which recommended reflecting impacts on productivity as a cost factor, our STF recognized that these are pragmatic choices and that there are cognitive limits to what can be assessed in a health state.

As depicted in a "value flower" (Appendix, available in online article), 3,10 we also recognized that several elements, related to uncertainty or spillovers to other family or members of society, are not well captured in current practice. Most notably, we emphasized that coverage of a new medicine by a health plan provides members with "insurance value" by providing them greater peace of mind through protection from financial hardship and from large risks to their health. Uncertainty can also be reduced if diagnostic tests or treatments provide (a) an option to access better treatments in the future (real option value), (b) a chance for a cure (i.e., the value of hope), or (c) the expectation of treatment benefit (value of knowing).

In addition, the development and use of new medicines or technologies can "spillover" to other stakeholders in the health care system. Drug development is inherently a global scientific endeavor whereby developers learn from the successes and failures of the colleagues who are competing to advance our understanding. ${ }^{10}$ These scientific externalities create an important systemic synergy and paying for only QALYs delivered (as opposed to also considering the knowledge gained) would overlook them. Furthermore, there are also concerns about equity of access and treatment. Even fear of contagion from epidemics, especially from emerging new viruses, can affect the peace of mind of all of those at risk-perhaps the entire plan membership.

Finally, given a threshold, effectiveness can be monetized to evaluate its net monetary benefit, making an ACEA into a benefit-cost analysis. ${ }^{3}$

Observation \#8: Health care systems must also make choices about new technologies, given current and future budget constraints, recognizing that choices imply there are inherent "opportunity costs." The health economics tool of a "cost-effectiveness threshold" can be helpful in weighing these trade-offs (Recommendations III \& IV).

To apply the cost-per-QALY metric, health economists have developed and operationalized the concept of willingness to 
pay for health gain, given resource constraints, as a threshold to support recommendations to accept or reject a new technology.

As producing new medicines become costlier, affordability and budget constraints become an increasingly important issue. Our STF recommended using the tool of cost-effectiveness thresholds to promote consistent and rational health plan decision making., ${ }^{4,7}$ Thresholds and budgets used to make coverage decisions from a payer perspective should — to the extent possible-reflect the willingness of consumers/taxpayers to pay for health and financial protection ex ante, that is, preferences for insurance before individuals require health care. ${ }^{4}$

Observation \#9: There are also some other factors or contextual considerations that may not be captured well in a costper-QALY approach or even an ACEA. Along with broader stakeholder deliberative processes, multicriteria decision analysis (MCDA) is a systematic and quantitative method for weighing a wider set of factors (Recommendation V).

Our STF also identified a number of potential value elements that are "conceptually feasible but generally impractical" for use in a QALY or augmented QALY approach. ${ }^{5}$ Other "process" elements, for example, might include fit with existing infrastructure and programs, availability of appropriately trained personnel, and effect on the educational sector. The "Impact Inventory" recommended by the U.S. Second Panel is intended to convey the components (inside and outside the health care sector) that have been considered by analysts.

Finally, given a threshold, an ACEA can be monetized to evaluate its net monetary benefit, becoming a benefit-cost analysis. $^{3}$

\section{Recommendations and Next Steps}

While all of the STF's recommendations are important, we highlight here this key take-away message:

Key Recommendation: Our ISPOR STF recommended further methods development and testing of alternative approaches that build on a cost-per-QALY metric, including ACEA and MCDA in support of deliberative processes.

We think it is important to begin considering and testing these alternative approaches in the context of managed care pharmacy but also believe that the cost-per-QALY metric can serve as the foundation or anchor for these alternative approaches-ACEA building on the cost-per-QALY metric and MCDA anchoring on the QALY (see Figure 1). These approaches should, however, be seen as complementary, with the appropriate combination varying with the specific health care resource allocation context. Three efforts-a value-based pricing initiative by the UK's National Institute for Health and Care Excellence that considered "wider societal benefit,"11 ICER in the United States incorporating "potential other benefits and contextual considerations,"12 and the U.S. Second Panel's broad Impact Inventory from a societal perspective-should be seen as important efforts to implement this research agenda. ${ }^{8,9}$ Furthermore, as reflected in the effort of the World Health Organization to encourage health technology assessment to support universal health coverage, ${ }^{13}$ we hope that health care systems worldwide-not only in the more than 110 countries with ISPOR members-recognize that they are interconnected in their evaluation methods and technology choices, which will ultimately determine the future direction of the science that generates new medicines to improve our collective well-being.

\section{Authors}

LOUIS P. GARRISON, JR., PhD, The Comparative Health Outcomes, Policy, and Economics (CHOICE) Institute, Seattle, Washington; PETER J. NEUMANN, ScD, Center for the Evaluation of Value and Risk in Health, Tufts University School of Medicine, Boston, Massachusetts; and RICHARD J. WILLKE, PhD, ISPOR, Lawrenceville, New Jersey.

AUTHOR CORRESPONDENCE: Louis P. Garrison, Jr., PhD, Professor Emeritus, The Comparative Health Outcomes, Policy, and Economics (CHOICE) Institute, Department of Pharmacy, University of Washington, Seattle, WA 98195-7630. Tel.: 206.427.0798;

E-mail: lgarrisn@uw.edu.

\section{DISCLOSURES}

No outside funding supported the writing of this article. The authors are leaders of the ISPOR Special Task Force on U.S. Value Frameworks. Willke is employed by ISPOR. Garrison and Neumann have nothing to disclose. The opinions expressed in this article should be considered as belonging only to the authors.

\section{ACKNOWLEDGMENTS}

The authors thank the other 10 members of the ISPOR Special Task Force on U.S. Value Frameworks for their contributions to the report, including sharing their important insights. The authors also benefited from the participation and efforts of other contributors to the effort, including supplement paper coauthors, participants in review groups, and discussants of the final report.

\section{REFERENCES}

1. Neumann PJ, Willke RJ, Garrison LP Jr. A health economics approach to US value assessment frameworks-introduction: an ISPOR Special Task Force report [1]. Value Health. 2018;21(2):119-23.

2. Garrison LP Jr, Pauly MV, Willke RJ, Neumann PJ. An overview of value, perspective, and decision context-a health economics approach: an ISPOR Special Task Force report [2]. Value Health. 2018;21(2):124-30.

3. Lakdawalla DN, Doshi JA, Garrison LP Jr, Phelps CE, Basu A, Danzon PM. Defining elements of value in health care-a health economics approach: an ISPOR Special Task Force report [3]. Value Health. 2018;21(2):131-39.

4. Danzon PM, Drummond M, Towse A, Pauly MV. Objectives, budgets, thresholds, and opportunity costs-a health economics approach: an ISPOR Special Task Force report [4]. Value Health. 2018;21(2):140-45 
Reflections on the ISPOR Special Task Force on U.S. Value Frameworks:

Implications of a Health Economics Approach for Managed Care Pharmacy

5. Phelps CE, Lakdawalla DN, Basu A, Drummond MF, Towse A, Danzon PM Approaches to aggregation and decision making-a health economics approach: an ISPOR Special Task Force report [5]. Value Health. 2018;21(2):146-54.

6. Willke RJ, Neumann PJ, Garrison LP, Ramsey SD. Review of recent U.S value frameworks - a health economics approach: an ISPOR Special Task Force report [6]. Value Health. 2018;21(2):155-60.

7. Garrison LP, Neumann PJ, Willke RJ, et al. A health economics approach to US value assessment frameworks - summary and recommendations of the ISPOR Special Task Force report [7]. Value Health. 2018;21(2):161-65.

8. Neumann PJ, Sanders GD, Russell LB, Siegel JE, Ganiats TG. CostEffectiveness in Health and Medicine. New York: Oxford University Press; 2016.

9. Sanders GD, Neumann PJ, Basu A, et al. Recommendations for conduct, methodological practices, and reporting of cost-effectiveness analyses: second panel on cost-effectiveness in health and medicine. JAMA. 2016;316(10):1093-103
10. Garrison LP, Kamal-Bahl, S, Towse, A. Toward a broader concept of value: identifying and defining elements for an expanded cost-effectiveness analysis. Value Health. 2017;20(2):213-16.

11. National Institute for Health and Care Excellence. Methodology for estimating "wider societal benefits" as the net production impact of treatments. Available at: https://www.nice.org.uk/Media/Default/About/what-we-do/ NICE-guidance/NICE-technology-appraisals/DH-Documentation-for-WiderSocietal-Benefits.pdf. Accessed September 27, 2019.

12. Institute for Clinical and Economic Review. Overview of the ICER value assessment framework and update for 2017-2019. Available at: http://icerreview.org/wp-content/uploads/2017/06/ICER-value-assessment-frameworkUpdated-050818.pdf. Accessed September 27, 2019.

13. World Health Organization. Using health technology assessment for universal health coverage and reimbursement systems. 2016. Available at: https://www.who.int/health-technology-assessment/HTA_November_meeting_report_Final.pdf. Accessed September 27, 2019. 
Reflections on the ISPOR Special Task Force on U.S. Value Frameworks:

Implications of a Health Economics Approach for Managed Care Pharmacy

\section{APPENDIX Augmented Cost-Effectivness Analysis for Comparison with MCDA}
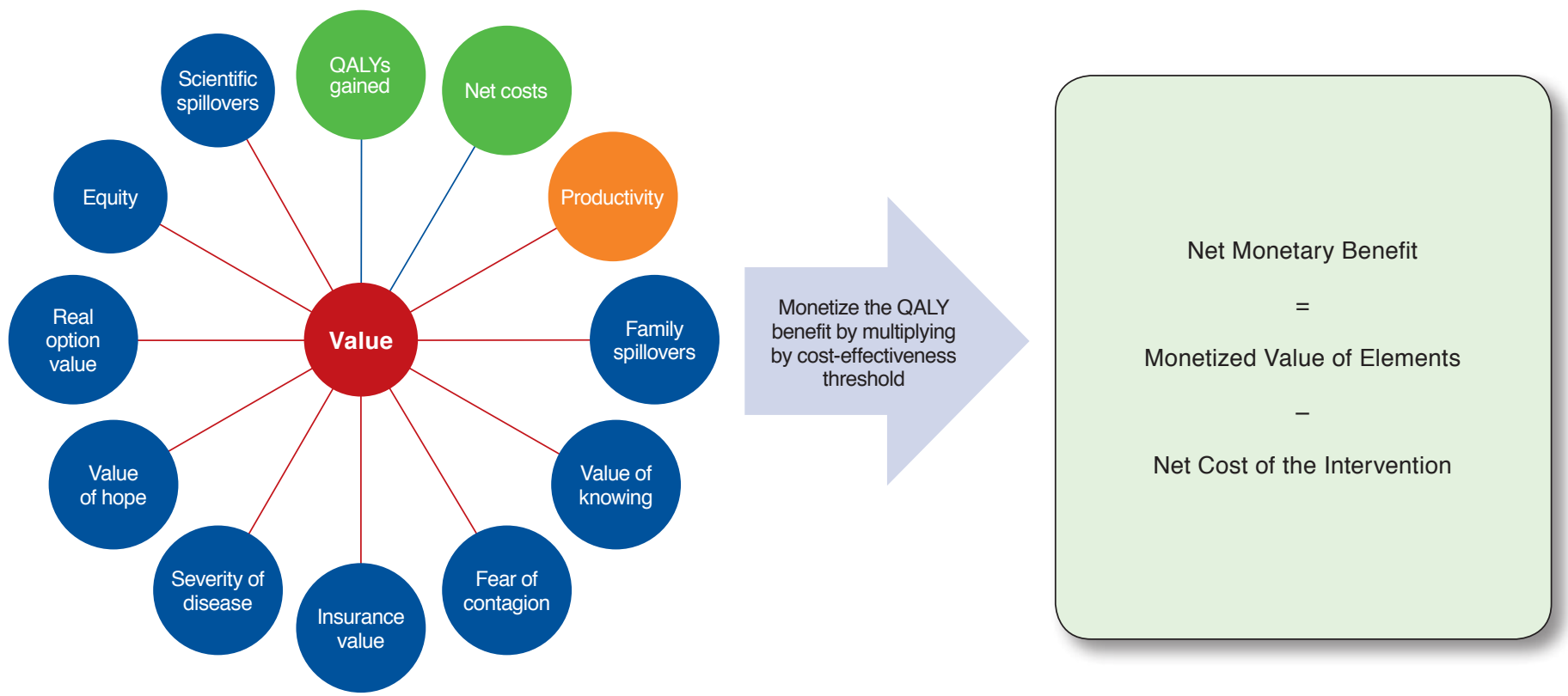

Core elements of value

Common but inconsistently used elements of value

- Potential novel elements of value

- Value element in traditional payer perspective

- Value element also included in societal perspective

Adapted from: Lakdawalla DN, Doshi JA, Garrison LP Jr, Phelps CE, Basu A, Danzon PM. Defining elements of value in health care-a health economics approach: an ISPOR Special Task Force Report [3], p. 132. ${ }^{7}$ Reprinted with permission.

$M C D A=$ multicriteria decision analysis; $Q A L Y=$ quality-adjusted life-year . 